\title{
Promoter analysis of genes that are coordinately expressed during pollen development reveals pollen-specific enhancer sequences and shared regulatory elements
}

\author{
David Twell,, Judy Yamaguchi, Rod A. Wing, ${ }^{2}$ James Ushiba, and Sheila McCormick ${ }^{3}$ \\ Plant Gene Expression Center, U.S. Department of Agriculture/Agricultural Research Service-University of \\ California-Berkeley, Albany, California 94710 USA
}

\begin{abstract}
We have investigated the functional organization and properties of cis regulatory elements in the promoter regions of two genes from tomato (LAT52 and LAT59) that are preferentially and coordinately expressed during pollen maturation. Promoter deletion analysis in transgenic plants demonstrated that only minimal $(<200 \mathrm{bp})$ promoter proximal regions are required for developmentally regulated expression in pollen and in specific cell types of the sporophyte. Cis-acting regulatory regions of these two promoters and of a third pollen-expressed promoter (LAT56) were characterized in detail using a transient expression assay. We identified two upstream activator regions in the LAT52 promoter and further showed that a 19-bp segment from one of those regions enhanced expression of the heterologous CaMV35S promoter in pollen. Similarities in sequence between crucial cis elements provide evidence that shared regulatory elements are involved in the coordinate expression of the LAT genes during microsporogenesis.
\end{abstract}

[Key Words: Tomato; tobacco; male gametophyte; transcriptional control; enhancer; cell-specific gene regulation]

Received September 28, 1990; revised version accepted January 4, 1991

Identifying the molecular components that control the spatial and temporal patterns of gene expression accompanying gametogenesis is an important step in understanding sexual reproduction in eukaryotes. We are interested in the development of the male gametophyte (pollen) of angiosperms because it provides a unique system with which to study cell-specific gene regulation and cellular differentiation during reproductive development in plants. Major cytological and biochemical events that occur during pollen development are well characterized, the mRNA populations in pollen have been analyzed, pollen-specific isoenzymes have been identified, and several genes that are preferentially expressed in pollen in a stage-specific manner recently have been cloned and sequenced (for reviews, see Mascarenhas 1975,1989 ). Of particular interest is the asymmetric mitotic division of the haploid microspore /microspore mitosis), which results in the formation of two dimorphic cells with different developmental fates. The

Present addresses: ${ }^{1}$ Leicester Biocentre, University of Leicester, Leicester LE1 7RH UK; ${ }^{2}$ Plant Science Center, Cornell University, Ithaca, New York 14853 USA.

${ }^{3}$ Corresponding author. vegetative cell supports pollen maturation and pollen tube growth, while the generative cell, completely contained within the vegetative cell, undergoes a further mitosis, resulting in the formation of two sperm cells. Microspore mitosis is therefore an important deterministic switch in pollen development, which is conserved among all known flowering plants. After mitosis a rapid synthesis of mRNA is initiated, resulting in the accumulation of mRNA in the mature desiccated pollen grain. Some of these mRNAs are presumably involved in pollen maturation, while others appear to be stored and translated upon pollen germination and/or pollen tube growth (for review, see Mascarenhas 1988).

We have characterized cDNA clones from tomato corresponding to mRNAs that accumulate following microspore mitosis and are either absent or present at highly reduced levels in sporophytic tissues (McCormick et al. 1987). Two of these cDNA clones (pLAT56 and pLAT59) encode proteins whose putative sequences are highly similar to one another (54\% amino acid identity) and that show significant sequence similarity to the pectate lyase genes of the plant pathogen Erwinia (Wing et al. 1989). This suggests that pectin degradation may be involved in pollen germination and/or pollen tube 
growth through the pistil. Another clone, pLAT52 (Twell et al. 1989b), shows $32 \%$ amino acid identity to a pollen-specific cDNA clone isolated from maize (Hanson et al. 1989).

The isolation of several genes that are similarly regulated during microsporogenesis provides an opportunity to identify sequence elements that are required for pollen-specific expression and to test the hypothesis that common regulatory elements are involved in their coordinate patterns of expression. We showed that the 5'-flanking regions of the LAT52 and LAT59 genes, when fused to the Escherichia coli $\beta$-glucuronidase (GUS) reporter gene (Jefferson et al. 1987), are sufficient to direct expression in an essentially pollen-specific manner in transgenic tomato, tobacco, and Arabidopsis plants (Twell et al. 1990). The expression of the 52-GUS and 59-GUS gene fusions was developmentally and coordinately regulated during microsporogenesis, similar to the pattern of mRNA accumulation for the endogenous genes, and was closely correlated with the onset of microspore mitosis (Twell et al. 1990).

In this paper we describe the results of experiments designed to delimit sequence elements within the upstream regions of the LAT52, LAT56, and LAT59 genes that are required for regulated gene expression during pollen development. Analyses of promoter deletion mutants fused to reporter genes in stably transformed plants (for the LAT52 and LAT59 promoters), or with a transient expression assay in pollen (Twell et al. 1989a), have allowed the precise identification of several cis-regulatory elements that are important for gene expression during pollen development. We present evidence for the function of two conserved regulatory elements, each of which is shared among two of the three LAT gene promoters. An upstream region of the LAT52 promoter that contains one of these conserved regulatory elements has the properties of an enhancer and is able to activate a heterologous core promoter in pollen.

\section{Results}

\section{Sequence comparison of the LAT gene promoters}

As a first step in our analysis of sequence elements required for the regulated expression of the LAT52, LAT56, and LAT59 genes during pollen development, their 5 '-flanking DNA sequences were compared to identify conserved motifs. The nucleotide sequence of $0.6 \mathrm{~kb}$ of $5^{\prime}$-flanking DNA of the LAT52 gene was described previously (Twell et al. 1989b). Sequences upstream of the coding regions of the LAT56 and LAT59 genes are shown in Figure 1. Pair-wise computer alignment of all three promoters showed no extensive regions of sequence similarity. However, the repeated sequence TGTGGTT, which we refer to as the PB core motif (Fig. 2a), was previously noted in the LAT52 promoter (Twell et al. $1989 \mathrm{~b}$ ) and is similar to the so-called SV40 enhancer core motif (Sassone-Corsi and Borrelli 1986) and to the binding site for the plant nuclear factor GT-1 (Green et al. 1988). The PB core motif is repeated three times within the 492 bp $5^{\prime}$ of the LAT52 transcription start site (Fig. 2a), and in the LAT56 promoter at position -166 bp (Fig. 1a) and the LAT59 promoter at position -508 bp (Fig. 1b). A 12-bp sequence that is shared between the LAT52 and LAT56 promoters (52/56 box; Fig. $2 \mathrm{~b})$ encompasses the $\mathrm{PB}$ core motif and is closely related to the box II sequence motif in the pea rbcS-3A gene promoter (Fig. 2a). Box II is representative of a class of cis-regulatory elements that are important for light-regulated and organ-specific gene expression (for review, see Gilmartin et al. 1990). A different sequence motif is shared between the LAT56 and LAT59 promoters. This motif, which we refer to as the $56 / 59$ Box (Fig. 2b), is present at a similar position relative to the transcription start site of both genes.

\section{Deletion analysis of the LAT promoters}

We showed previously that $0.6 \mathrm{~kb}$ of the LAT52 and 1.4 $\mathrm{kb}$ of the LAT59 5'-flanking DNA regions are sufficient to direct expression exclusively in gametophytic cells (pollen) of developing anthers (Twell et al. 1989b). To identify and characterize cis-regulatory elements involved in promoter strength and specificity, $5^{\prime}$ and internal deletion mutants of the LAT promoters were constructed in vitro and linked to the coding region of the GUS reporter gene (Jefferson et al. 1987). Transfer of the chimeric genes to tomato plants allowed us to localize promoter activity in transgenic plants. A transient assay system in tobacco pollen (Twell et al. 1989a) allowed us to examine the effect on expression of many more promoter mutations than is practical in transgenic plants.

LAT52 promoter activity in transgenic plants LAT52 promoter activity in various tissues was initially examined by quantitative assay of GUS activity in extracts from pooled tissues of the primary transformants. No significant increase above background GUS activity (in extracts from untransformed plants) was detected in plants containing the 52-GUS deletion mutants for the following tissues: stem, leaf, sepal, petal, pistil, and pericarp of green or red fruit (data not shown), with the exception of the -3000 - and -492-bp 52-GUS deletion mutants, which showed low levels of activity in those tissues relative to anthers. However, the sporophytic activity observed for the -3000 - and $-492-b p$ deletion mutants was accounted for by 1 of 4 independent -3000 -bp transformants and 2 of 10 independent -492-bp transformants (data not shown), and are presumed to be due to position effects.

Whole anthers containing pollen can be assayed for GUS activity as a measure of the GUS activity in pollen (Twell et al. 1990). Deletion of the LAT52 promoter from -3000 to $-492 \mathrm{bp}$ did not significantly affect promoter activity in pollen (Fig. 3a). However, deletion to $-145 \mathrm{bp}$ reduced promoter activity $\sim 10$-fold. Deletion to $-86 \mathrm{bp}$ further reduced promoter activity 100 -fold. The deletion mutants -86 bp $52-$ GUS and -71 bp 52-GUS showed similar levels of GUS activity, which was $\sim 20$-fold above background levels. These results demonstrate that 


\section{Twell et al.}

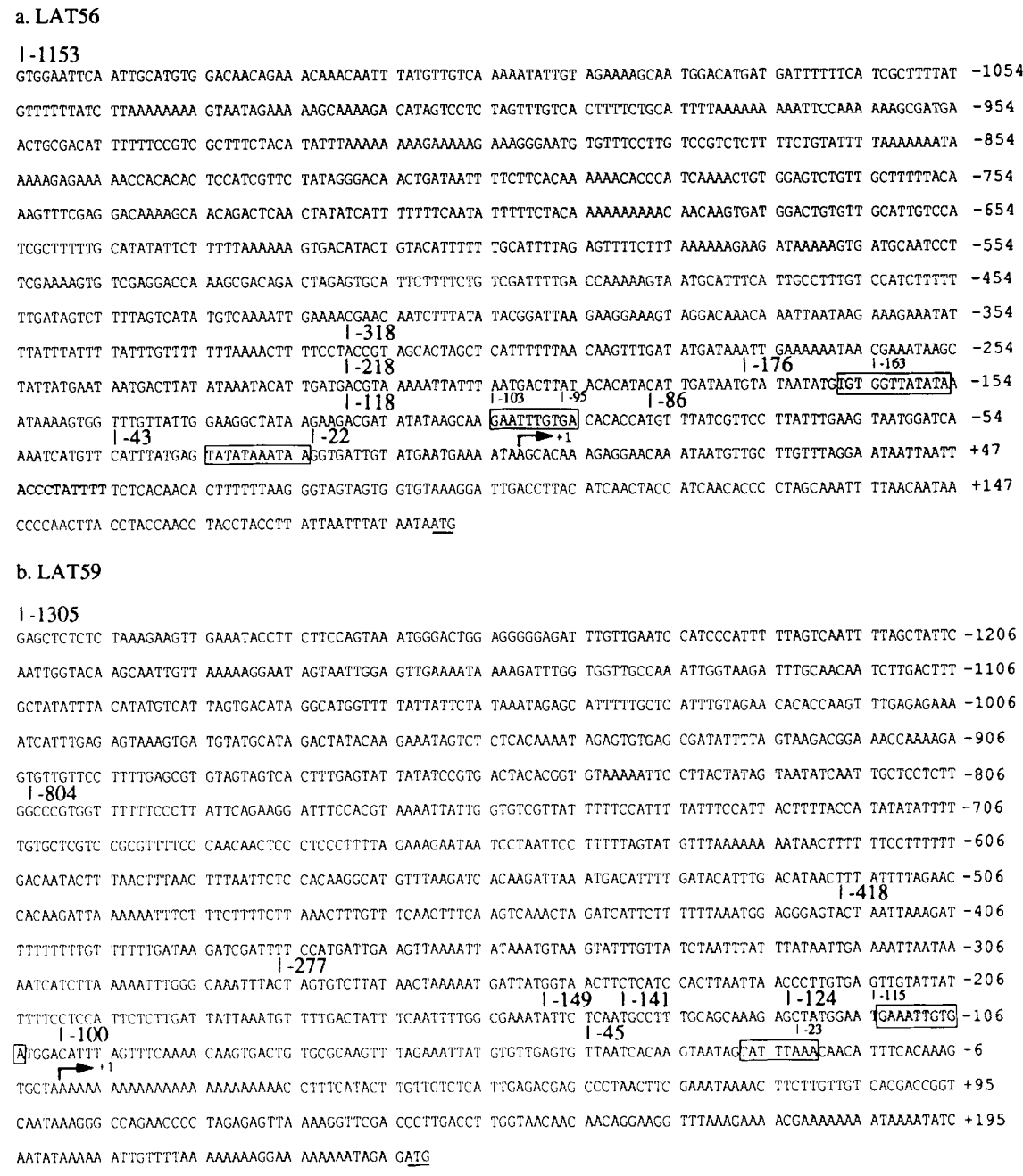

Figure 1. DNA sequences of the 5 -flanking regions of the $\operatorname{LAT5} 6(a)$ and LAT59 (b) genes. The transcription (arrows and translation (underlined) start sites, pu tative TATA boxes (open boxes) and functionally conserved regulatory elements be tween the LAT52, LAT56, and LAT59 promoters (shaded boxes) are noted. The endpoints of the $5^{\prime}$ deletion mutants are indicated above the sequence with a vertical line.

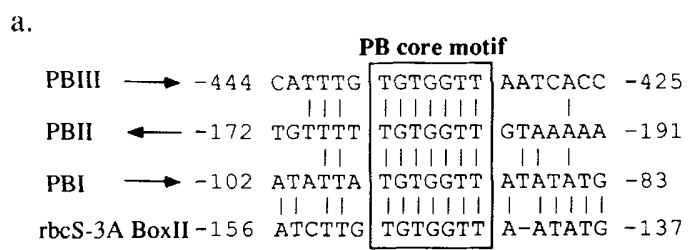

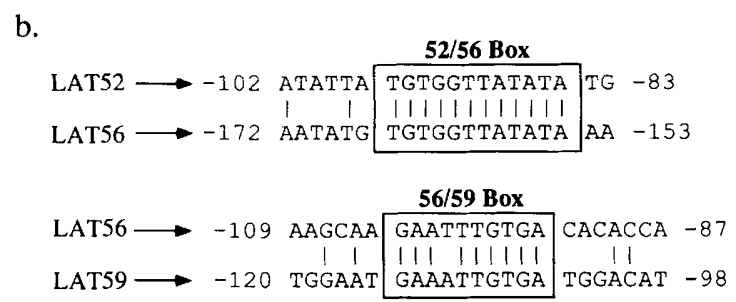

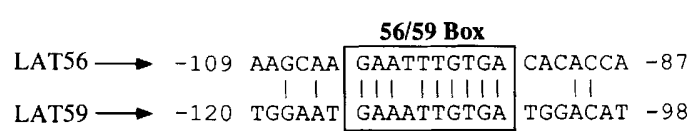

at least three distinct regions of the LAT52 promoter (Fig. 4a) regulate gene expression in pollen. Regions 52-A $(-492 \mathrm{bp}$ to $-145 \mathrm{bp})$ and $52-\mathrm{B}(-124 \mathrm{bp}$ to $-86 \mathrm{bp})$ contain sequences that strongly enhance expression in pollen. However, region $52-\mathrm{C}(-71 \mathrm{bp}$ to $+110 \mathrm{bp})$ is sufficient to direct gene expression in pollen.

Previous analysis demonstrated that LAT52 promoter activity was localized in developing pollen grains after microspore mitosis (Twell et al. 1990). We found that all of the LAT52 deletion mutants directed GUS expression that was developmentally and spatially similar (Fig. 5B and data not shown/ to that observed for the endogenous LAT52 gene (Twell et al. 1989b, 1990).

The 52-GUS deletion mutants all showed GUS activity in immature and mature seeds (Fig. 3b). GUS activity in the 52-GUS deletion mutants was restricted to the endosperm (Fig. 5F), whereas seeds from a transgenic tomato plant containing a cauliflower mosaic virus $35 \mathrm{~S}$ (CaMV35S) promoter-GUS construct showed high levels of GUS activity in all seed tissues (not shown). Only 6 of the 26 independent transformants examined showed detectable staining in roots. We attribute this root expres-
Figure 2. Conserved sequence motifs in the LAT gene promoters. Identities between pairs of sequences are shown as vertical lines, and orientation relative to the transcription start site is indicated by arrows. $(a)$ Extended sequence similarity around the reiterated PB core motif (boxed) in the LAT52 promoter and in the rbcS-3A promoter. (b) Conserved $52 / 56$ box and $56 / 59$ box sequences. 
a. LAT52: ANTHERS

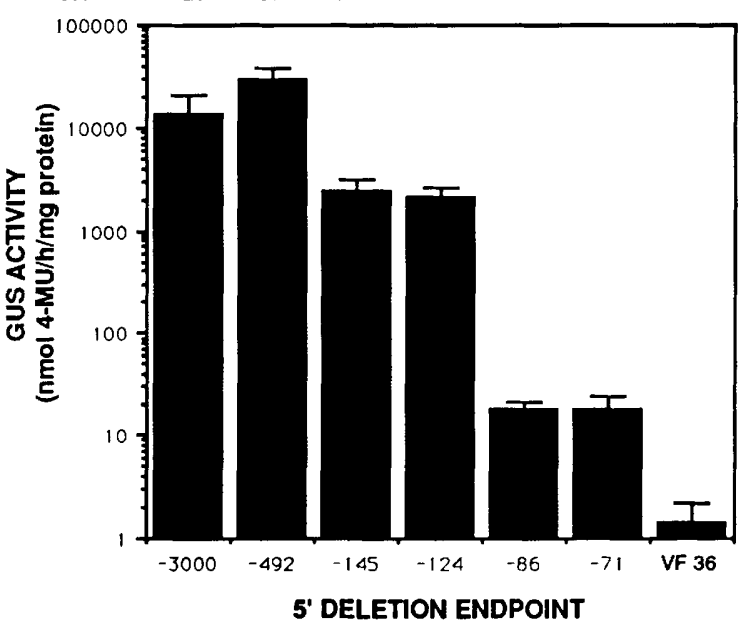

b. LAT52: SEEDS

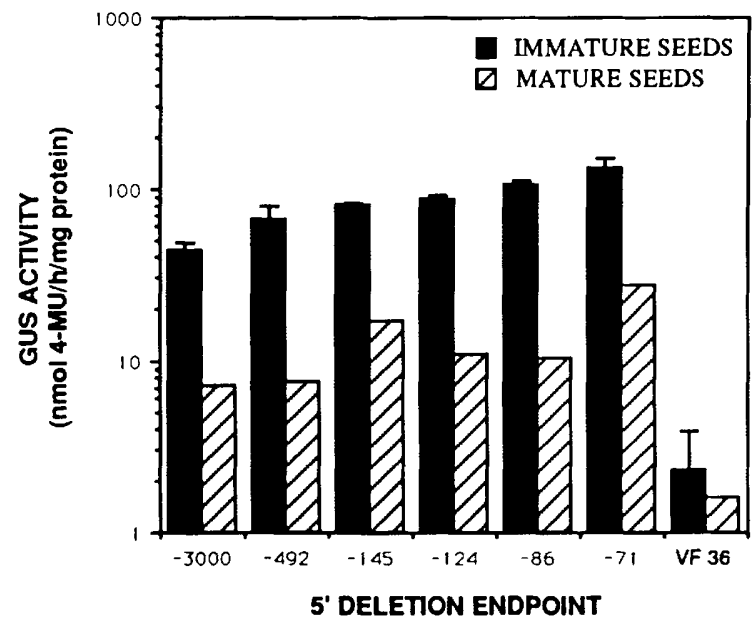

C. LAT59: ANTHERS

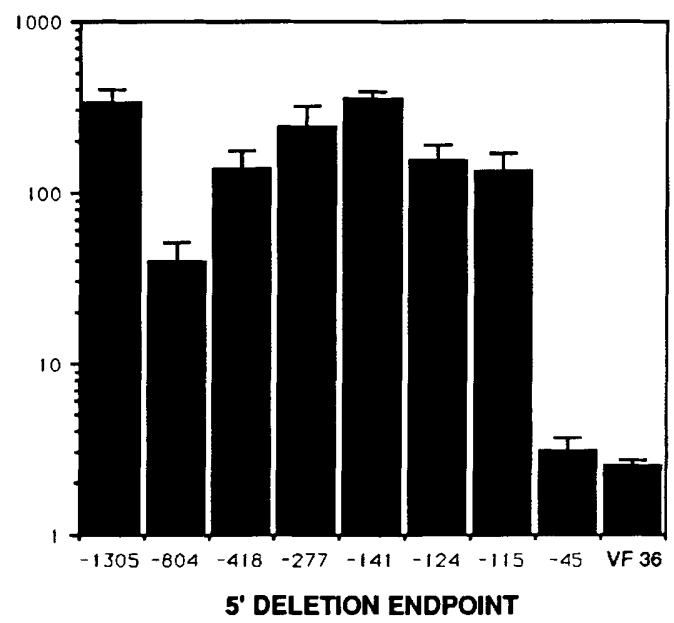

d. LAT59: SEEDS

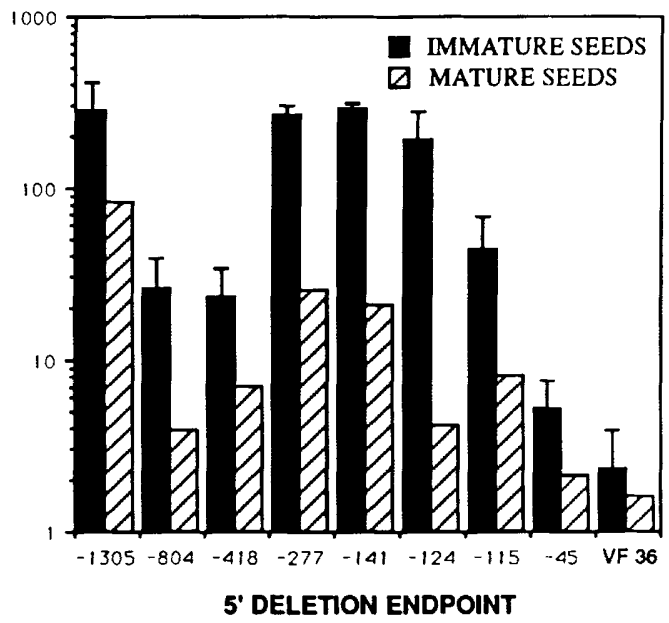

Figure 3. Promoter activity of $5^{\prime}$ deletion mutants in transgenic tomato plants. GUS activity in anthers $(a$ and $c)$ and seeds $(b$ and $d)$ of LAT52 $(a$ and $b)$ and LAT59 $(c$ and $d)$ promoter deletion mutants. The data for anthers and immature seeds represent the mean activity of three separate determinations of GUS activity in extracts prepared from pooled tissues taken from 4-12 independent transformants; error bars indicate the S.D. The mature seed values are from one determination per deletion mutant. Control assays (VF36) were performed on untransformed tomato plants.

sion to position effects, because there was no correlation with the level of pollen expression, deletion end point, or cellular pattern of staining (data not shown).

LAT52 promoter activity in the transient assay system We showed previously that the activities of the LAT52 and CaMV35S promoters in transient expression assays, in which DNA is delivered into tobacco pollen by microprojectile bombardment, closely reflected the activities of the LAT52 and CaMV35S promoters in transgenic tomato plants (Twell et al. 1989a, 1990).

The $5^{\prime}$ deletion analysis using this transient assay (Fig. 6a) confirmed the activity of the promoter regions 52-A, $52-\mathrm{B}$, and $52-\mathrm{C}$ and further defined subregions of importance (52-A1, 52-A2, 52-B1, and 52-C1, Fig. 4a). The upstream activation properties of the $52-\mathrm{A}$ region were analyzed (Fig. 7a) in the absence of 52-B. Two copies of 52-A in tandem led to an approximately twofold increase in promoter activity (cf. pLAT52-20 and pLAT52-31; Fig. $7 \mathrm{a})$, which demonstrates that this region can function in an additive manner when placed $0.5 \mathrm{~kb}$ upstream of the transcription start site. Removal of region 52-Al / -492 bp to $-225 \mathrm{bp}$ / led to an approximately twofold decrease in activity (cf. pLAT52-20 and pLAT52-28; Fig. 7a). The activity of $52-\mathrm{A} 1$ was not revealed by analysis of $5^{\prime}$ deletion mutants when 52-B was intact (cf. -492 and -225 bp deletion mutants; Fig. 6 a), so these data provide evidence for redundant enhancer sequences in the $52-\mathrm{Al}$ and $52-\mathrm{B}$ regions. The region $-225 \mathrm{bp}$ to $-129 \mathrm{bp}$ $(\sim 52-\mathrm{A} 2)$, when placed upstream of the truncated -86-bp LAT52 promoter, enhanced expression additively and independent of orientation $>10$-fold (pLAT5228, pLAT52-29, pLAT52-30, and pLAT52-17; Fig. 7a). A 50 -bp fragment $(-225$ to $-176 \mathrm{bp})$ containing the PB motif also enhanced the activity of the core promoter 
Twell et al.
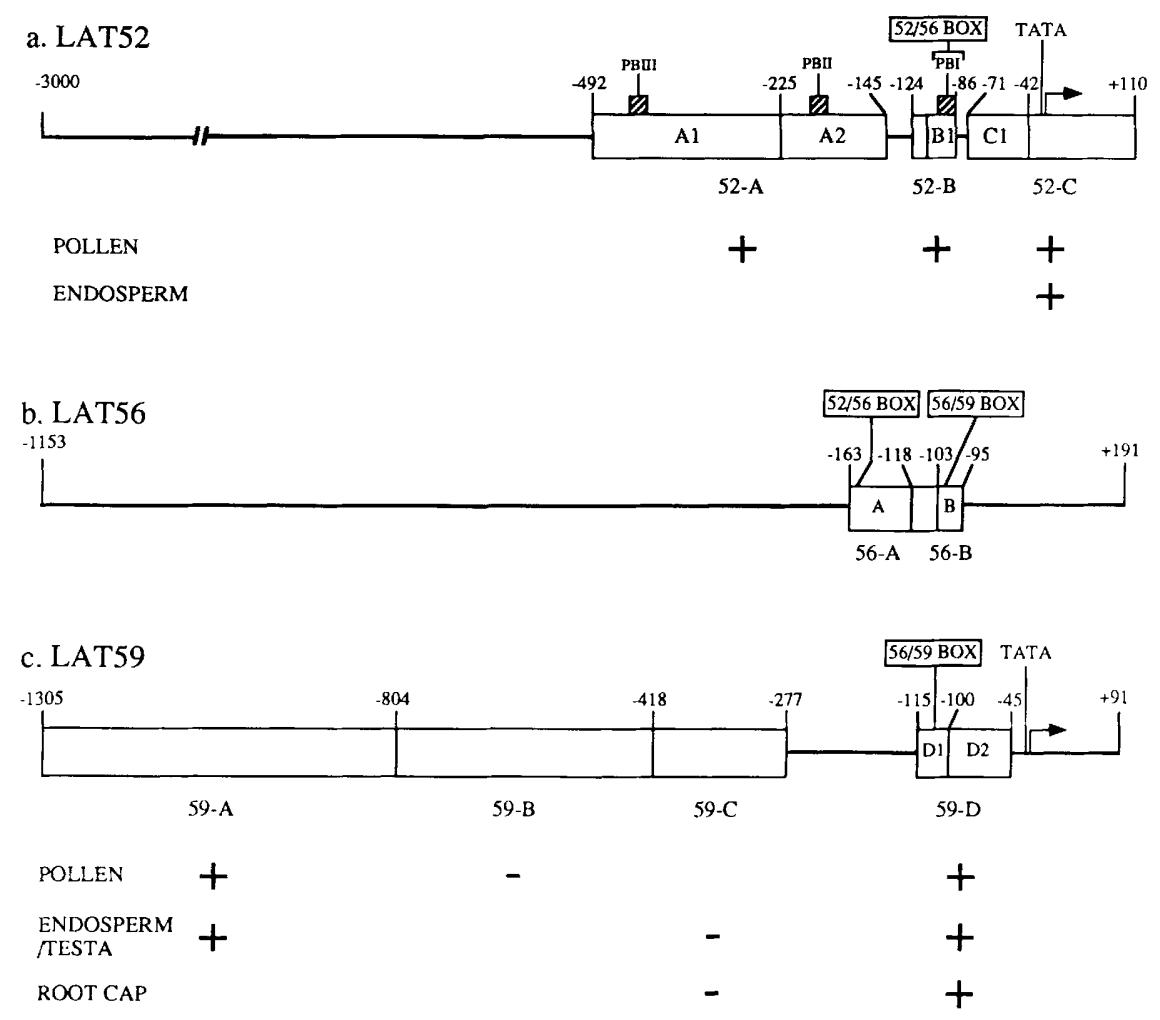

Figure 4. Functional maps of the LAT gene promoters. Diagrams of the LAT52, LAT56, and LAT59 promoter regions as defined by transient expression and/or transgenic plant assays are shown (see text). approximately fivefold, independent of its orientation (pLAT52-49 and pLAT52-47; Fig. 7a).

To examine whether the $52-\mathrm{A} 2$ region could enhance the activity of a heterologous promoter, the 52-A2 fragment and smaller portions of it were placed upstream of a truncated CaMV35S promoter (Ow et al. 1986) and tested using the transient expression assay. As shown in Figure $7 \mathrm{~b}$, a single copy of 52-A2 in reverse orientation enhanced the activity of the -89 -bp CaMV35S promoter $\sim 14$-fold, and two tandem copies led to an $\sim 25$-fold enhancement. A 19-bp oligonucleotide containing the PBII sequence was placed upstream of the -89 -bp CaMV35SLUC fusion. A single copy of this sequence enhanced expression in the forward and reverse orientations $\sim 4$ and $\sim 7$-fold, respectively (Fig. 7 b), while two copies in a tail-to-tail configuration enhanced expression $\sim 15$-fold. These results show that the PBII box acts as a transcriptional enhancer in pollen. Control experiments showed that increasing the length of the CaMV35S promoter to -148 bp or -1500 bp did not significantly activate gene expression in pollen (Fig. 7b).

The $5^{\prime}$ deletion analysis within the $52-\mathrm{B}$ region $(-145$ $\mathrm{bp}$ to $-86 \mathrm{bp}$ ) identified cis-regulatory sequences in the region -100 to $-86 \mathrm{bp}(52-\mathrm{B} 1)$, which contains the 52 / 56 box. Partial deletion of the $52 / 56$ box /cf. -100 - and -93-bp deletions; Fig. 6a) led to a twofold decrease in promoter activity. Deletion of region $52-\mathrm{C}$ from -71 to -42 bp (52-C1) led to a threefold decrease in activity (Fig. 6a). Since 52-C is sufficient for specific expression in pollen and endosperm of transgenic plants, these results indicate that the $52-\mathrm{Cl}$ region is responsible, at least in part, for the pollen component of this expression pattern. Further deletion from -42 to -17 bp (Fig. 6a), which removed the putative TATA box, abolished detectable expression.

LAT56 promoter activity in the transient assay system Because we had identified shared motifs between the LAT56 promoter and the LAT52 and LAT59 promoters, we used the pollen transient assay to perform a $5^{\prime}$ deletion analysis of the LAT56 promoter to assess whether the shared motifs were important. Promoter activity of $5^{\prime}$ deletion mutants of the LAT56 promoter in pollen identified two positive regulatory regions (Figs. $4 \mathrm{~b}$ and $6 \mathrm{~b})$. Deletion of $56-\mathrm{A}(-163$ to $-118 \mathrm{bp}$ ) led to an approximately fivefold decrease in promoter activity. The 56-A region contains the shared $52 / 56$ box sequence (Fig. 2b). Deletion of 56-B (-103 to $-95 \mathrm{bp}$ ) led to an approximately fourfold decrease in activity. This region contains the shared $56 / 59$ box (Fig. 2b). Deletions in the -95- to -22 -bp region showed no further decreases in promoter activity (Fig. 6b).

LAT59 promoter activity in transgenic plants In contrast with the LAT52 promoter, deletion analysis identified no strong upstream activating sequences in the LAT59 promoter (Fig. 3c). Deletion of the LAT59 promoter to -115 bp gave only a slight decrease in promoter activity (two- to threefold) compared with the - 1305-bp 59-GUS fusion. Further deletion to $-45 \mathrm{bp}$, which retained the putative TATA box, abolished detectable expression. Regulatory elements located between -115 and -45 bp (59-D, Fig. 4c) thus appear to be largely responsible for the activity of the LAT59 pro- 

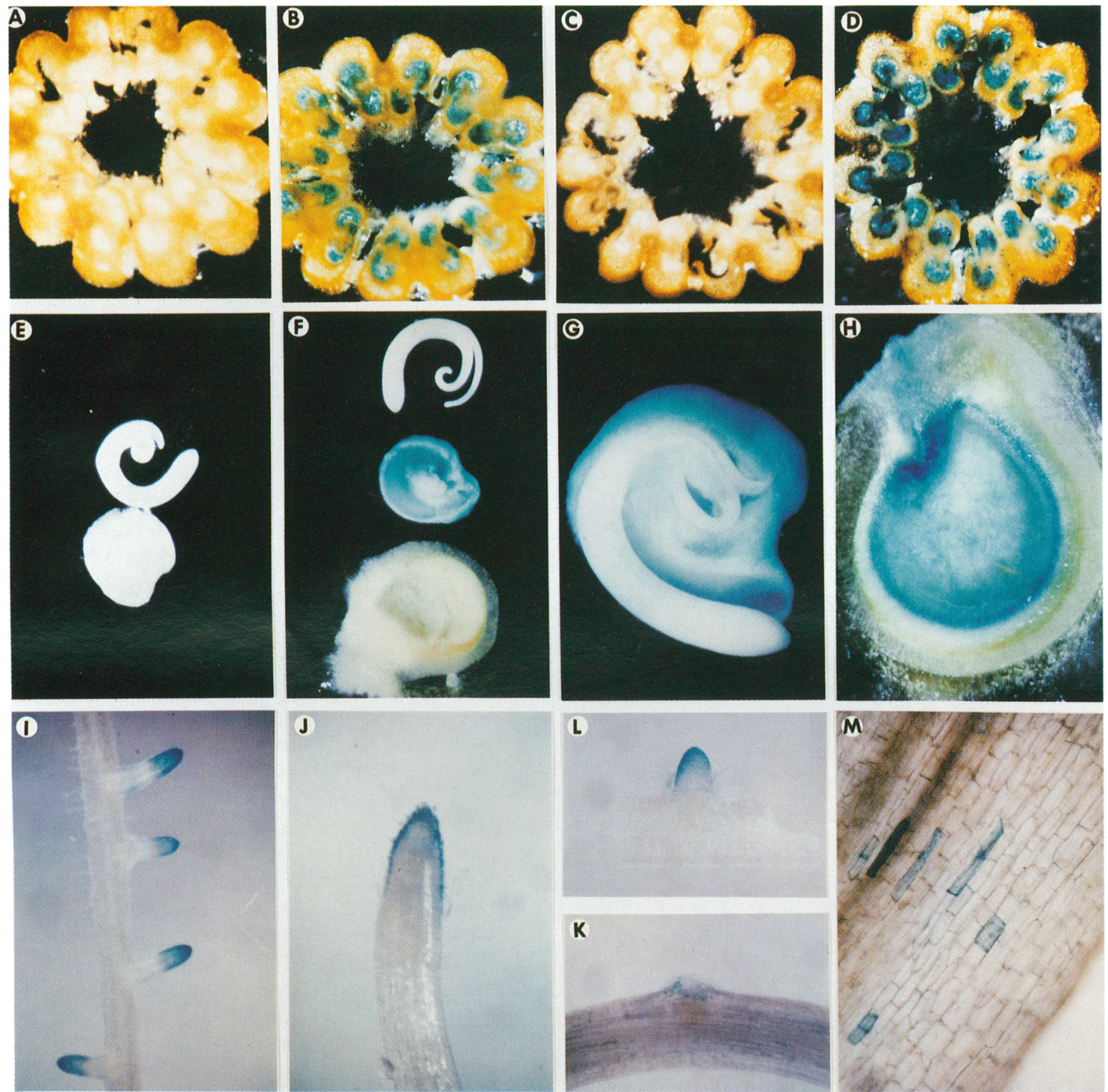

Figure 5. Localization of GUS activity in anthers, seeds, and roots of representative transgenic tomato plants. $(A)$ Anther section from untransformed tomato cv. VF36; $(B)$ anther section from - 71-bp 52-GUS plant; $(C)$ anther section from - 45-bp 59-GUS plant; $\{D \mid$ anther section from - 115-bp 59-GUS plant; $(E)$ embryo and endosperm section from VF36; $(F)$ embryo, endosperm, and testa section from - 71-bp 52-GUS plant; $(G)$ embryo and endosperm section from - 124-bp 59-GUS plant; $(H)$ testa section from - 140-bp 59-GUS plant; $(I)$ root segment from - 277-bp 59-GUS plant; $(J)$ longitudinal section of tip of a primary root from - 277-bp 59-GUS plant; $(K)$ root segment from - 124-bp 59-GUS plant before emergence of the lateral root meristem; $(L)$ recently emerged lateral root from - 124-bp 59-GUS plant; $(M)$ root segment from - 1305-bp 59-GUS plant.

moter in pollen. The data shown in Figure $3 \mathrm{c}$ also provide evidence for a negative regulatory element located between -804 and $-418 \mathrm{bp}$ (59-B, Fig. $4 \mathrm{c}$ ), and a positive regulatory element located between -1305 and $-804 \mathrm{bp}$ (59-A, Fig. 4c), since the activity of the -804-bp 59-GUS deletion mutant is reduced 5- to 10 -fold relative to the flanking deletion mutants. As with the minimal LAT52 promoter, the minimal LAT59 promoter $(-115 \mathrm{bp})$ directed GUS expression that was spatially and developmentally similar (Fig. 5D; data not shown) to that of the endogenous LAT59 gene (Wing et al. 1989).
Our previous analysis showed that the - 1305-bp 59GUS fusion was also expressed at low levels in seeds and roots of transgenic tomato plants (Twell et al. 1990). Although we were unable to detect the endogenous LAT59 transcript in these tissues (Twell et al. 1990), this deletion analysis revealed the location of cis-acting regions that specify sporophytic expression of the 59-GUS fusion. GUS activity was detected in both immature and mature seeds of all but the -45 -bp 59-GUS deletion mutant (Fig. 3d). GUS activity in seeds was localized to both the endosperm and the testa (Fig. 5G,H). Deletion 


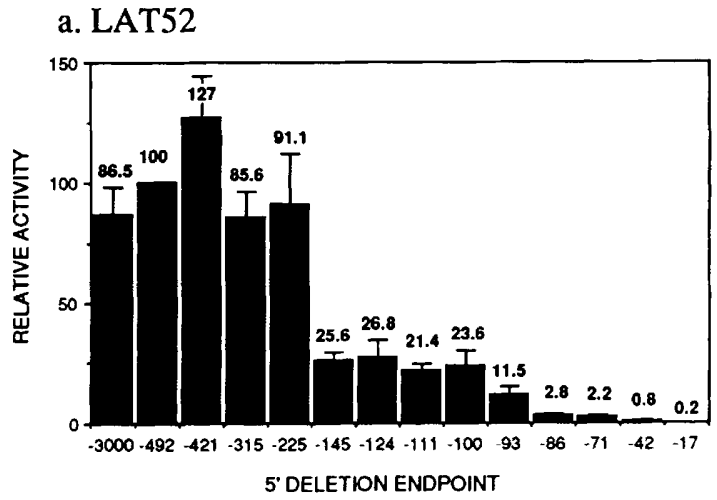

b. LAT56

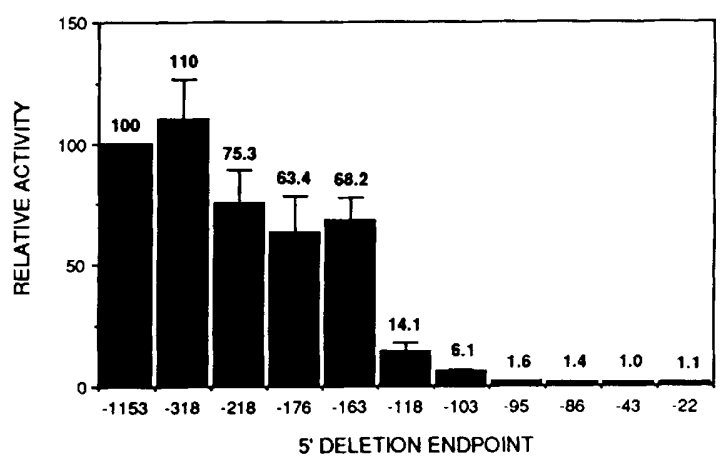

c. LAT59

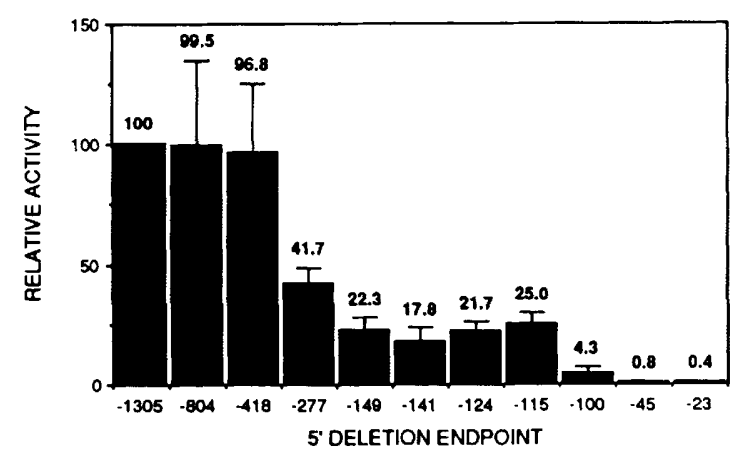

Figure 6. Transient expression analysis of 5 ' deletion mutants of LAT promoters in tobacco pollen. Test plasmids were cobombarded with the reference plasmid pLAT59-13 and assayed for GUS (test) and LUC (reference) activity after 6-12 hr. Relative activity represents the GUS/LUC ratio for each deletion mutant, normalized to the activity of the -492 -bp 52-GUS deletion mutant $(a)$, the -1153 -bp 56-GUS deletion mutant $(b)$, or the -1305-bp 59-GUS deletion mutant (c). Relative activity represents the mean of at least five independent bombardments. Error bars show the S.D.

from -1305 to $-804 \mathrm{bp}(59-\mathrm{A})$ led to a significant $(\sim 10$-fold $)$ decrease in promoter activity, and deletion from -115 to -45 bp led to a 26 -fold decrease in GUS activity (Fig. 3d). These results indicate the presence of positive regulatory elements for seed expression in the 59-A and 59-D regions (Fig. 4c). Low levels of seed expression were observed for the -804-bp 59-GUS and -418-bp 59-GUS deletion mutants, which indicates that negative regulatory elements are located in the -418- to -277 -bp (59-C) region (Figs. $3 \mathrm{~d}$ and $4 \mathrm{c}$ ).

GUS activity was consistently detected in roots of tomato plants containing the $-1305-,-277-,-141-$, -124-, and - 115-59-GUS deletion mutants, but not in roots of the $-804-,-418-$, and -45 -bp deletion mutants. These results suggest that the 59-D region (Fig. 4c) contains sequences required for expression of the 59GUS fusion in roots, while region 59-C (Fig. 4c) appears to have a negative influence on root expression. With the exception of the -1305-bp 59-GUS deletion mutant, roots showed staining in the root cap of both primary and lateral roots (Fig. 51,J) but not in the root meristem, cortex, or vascular tissue. In lateral roots, staining was first detected in epidermal cells that are dislodged during lateral root emergence (Fig. $5 \mathrm{~K}$ ) and then in the root cap immediately after emergence (Fig. $5 \mathrm{~L}$ ). In contrast, the - 1305-bp 59-GUS deletion mutant roots showed a punctate pattern (i.e., staining in isolated cells) distal from the root tip (Fig. 5M).

Our results indicate that the expression of the 59-GUS fusion in roots is mainly associated with sites of lateral root emergence and the presence of the root cap. If the LAT59 gene product encodes a functional pectate lyase (Wing et al. 1989), we would propose a role for this protein in cell separation events that occur during the emergence of lateral roots, and in the sloughing off of root cap cells. Immunolocalization studies are required to establish whether the observed GUS staining patterns reflect the endogenous distribution of the LAT59 gene product in roots.

LAT59 promoter activity in the transient assay system Deletion of the 59-D region (Fig. $4 \mathrm{c}$ ) led to a 31 -fold decrease in promoter activity in the transient assay (Fig. $6 \mathrm{c}$ ), similar to that observed upon deletion of 59-D in transgenic plants (Fig. 3c). Deletions from -115 to -100 $\mathrm{bp}$, the region that contains the shared $56 / 59$ Box sequence (Fig. $2 \mathrm{~b}$ ), and from -100 to $-45 \mathrm{bp}$, each led to a five- to sixfold decrease in promoter activity (Fig. 6c). This indicates the presence of at least two regulatory regions within the 59-D region, which we refer to as 59-D1 and 59-D2 (Fig. 4c). Further deletion from -45 to $-23 \mathrm{bp}$, removing the putative TATA box, led to a twofold decrease in activity (Fig. 6c). In the upstream region, deletion from -418 to $-115 \mathrm{bp}$ led to a fourfold decrease in promoter activity, due to two contiguous regulatory regions, -418 to $-277 \mathrm{bp}(59-\mathrm{C})$ and -277 to $-149 \mathrm{bp}$ (Figs. 6c and 4c, respectively).

In summary, the importance of the 59-D region was confirmed with both the transient and transgenic analyses. The positive influence of the -418 - to -115 -bp region was not observed in pollen of transgenic plants (Fig. $3 c)$, although it influenced promoter activity in the transient assay (Fig. 6c). Furthermore, the negative influence of the 59-B region ( -804 to $-418 \mathrm{bp}$ ) observed in transgenic plants (Fig. 3c) was not detected using the transient assay (Fig. 6c). This lack of correlation between transient and stable analyses of the upstream regulatory elements of the LAT59 promoter could be due to insufficient levels of available trans-acting factors in mature or recently 


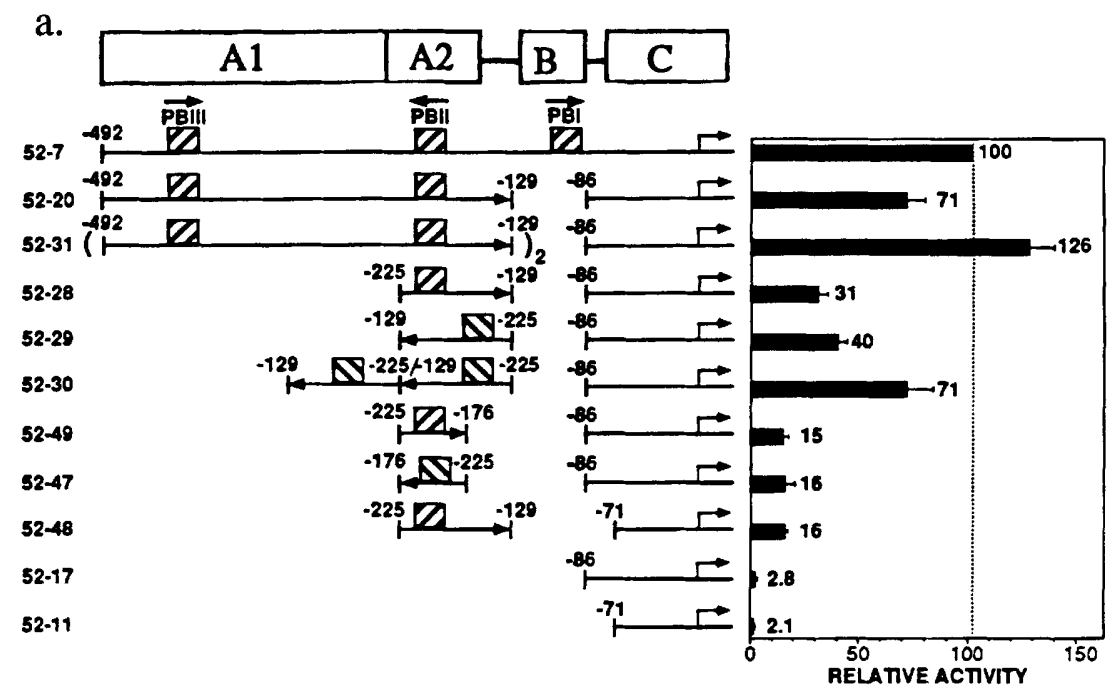

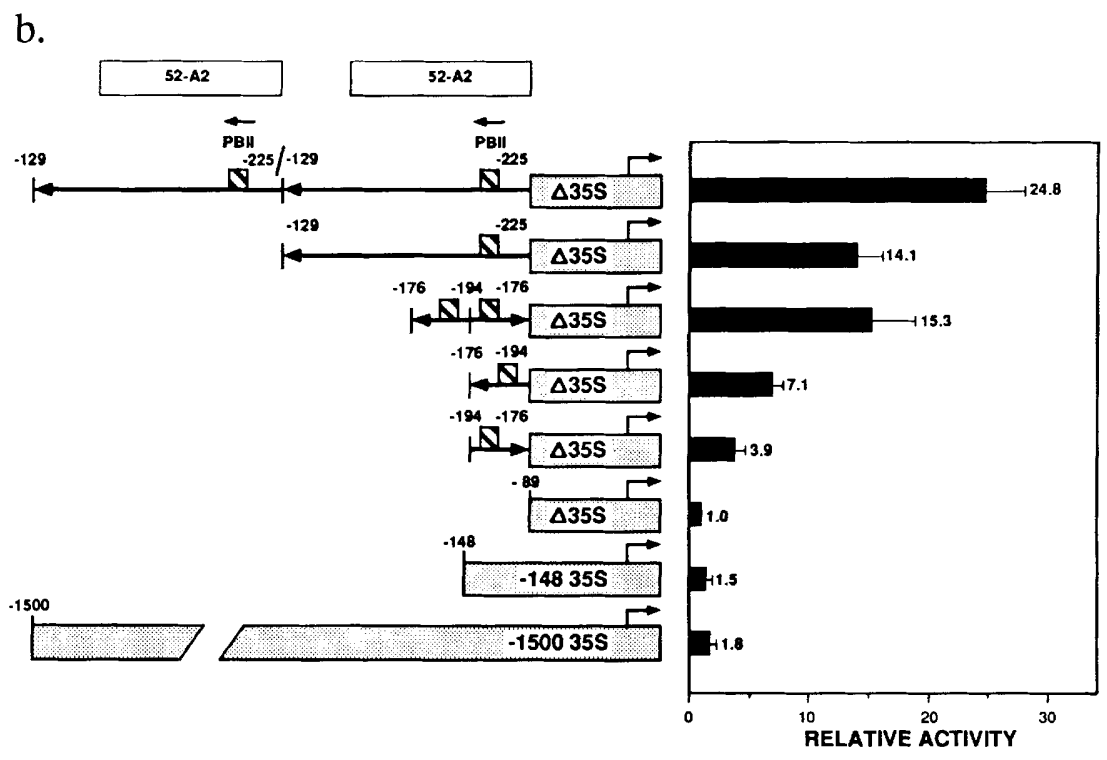

Figure 7. Analysis of LAT52 upstream elements. PBI, PBII, and PBIII (hatched boxes) represents the position and orientation of the reiterated TGTGGTT motif in the LAT52 promoter. Relative activity represents the mean of at least six independent bombardments. Error bars show the s.D. $|a|$ Activation of a truncated LAT52 promoter by upstream sequences from the LAT52 promoter. Transient expression assays were performed as described in Fig. 6. Plasmid names are listed at left. (b) Activation of a truncated CaMV35S promoter by upstream sequences from the LAT52 promoter. The activities of hybrid promoter constructs linked to LUC were determined by transient expression assays as described in Fig. 6, using pLAT59-12 $\mid-1305$-bp 59GUS fusion) as the reference plasmid. CaMV35S promoter sequences are indicated as stippled boxes. $(\Delta 35 S)-89$-bp CaMV35S promoter. hydrated pollen, or due to the use of pollen from tobacco, a heterologous plant. It is also possible that the lower GUS expression in the transgenic plants we analyzed for the -804 and $-418-b p$ deletions was due to position effects.

\section{Analysis of common regulatory elements in the LAT promoters}

Mutation of the GG doublet in the $52 / 56$ box sequence of the LAT52 promoter led to a 10 -fold decrease in promoter activity $\left(-1005^{\prime}\right.$ del GG $>$ CA; Fig. 8a); removing the GG doublet from the $52 / 56$ Box in the LAT56 promoter resulted in a 2 -fold decrease in expression $(-161$ 5 ' del; Fig. 8b). Mutation of an additional downstream GG doublet in the LAT56 promoter did not lead to a further decrease in activity $\mid-1615^{\prime}$ del GG $>$ CA; Fig. $8 \mathrm{~b})$.
Substitutions of 2 or 3 bp were introduced in the $56 / 59$ box of the LAT59 promoter (S1 to S8; Fig. 8c). Mutants of the core motif GTGA led to an approximately threefold decrease in promoter activity. The equivalent mutation in the $56 / 59$ box in the LAT56 promoter also abolished the activity of the 56-B region (Fig. 8b). These experiments demonstrate the importance of the $56 / 59$ box (Fig. $2 \mathrm{~b})$ in both the LAT56 and LAT59 promoters.

\section{Conservation of LAT gene regulatory elements in other pollen-expressed genes}

In addition to the LAT genes, the upstream regions of two other genes that are similarly regulated during pollen development have been sequenced: the maize $\mathrm{Zmg} 13$ gene (Hamilton et al. 1989), the coding region of which shares sequence similarity with that of LAT52, and the petunia chalcone flavone isomerase (chi) A gene (van 
Twell et al.

Figure 8. Functional analysis of shared regulatory elements in the LAT gene promoters. Transient expression assays in tobacco pollen were performed as described in Fig. 6. (a) Deletion and substitution mutants in the LAT52 promoter region containing the conserved $52 / 56$ box (stippled). $(b)$ Deletion and substitution mutants in the LAT56 promoter region containing the conserved $52 / 56$ box (stippled) and the $56 / 59$ box (hatched). (c) Substitution mutants in the LAT59 promoter region containing the $56 / 59$ box (hatched). Relative activity represents the mean of at least four independent bombardments. $(\mathrm{SD})$ Standard deviation. a.

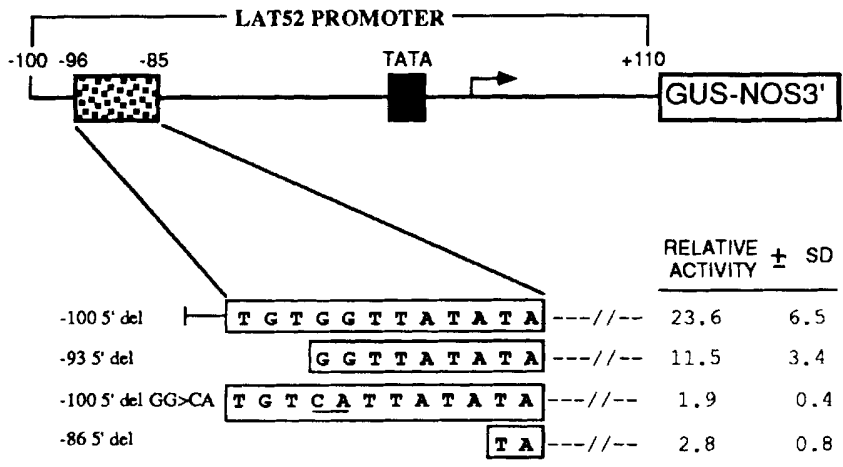

b.

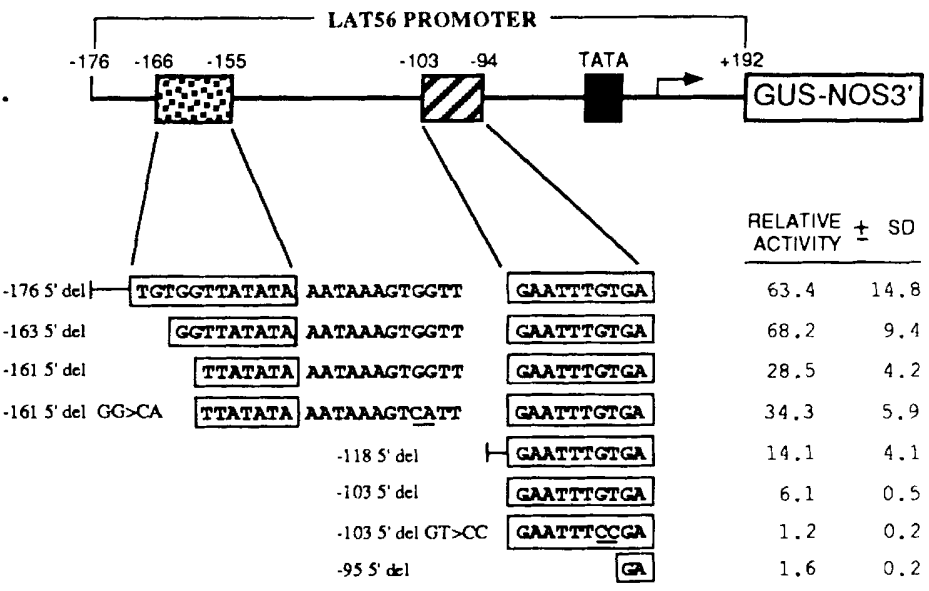

c.

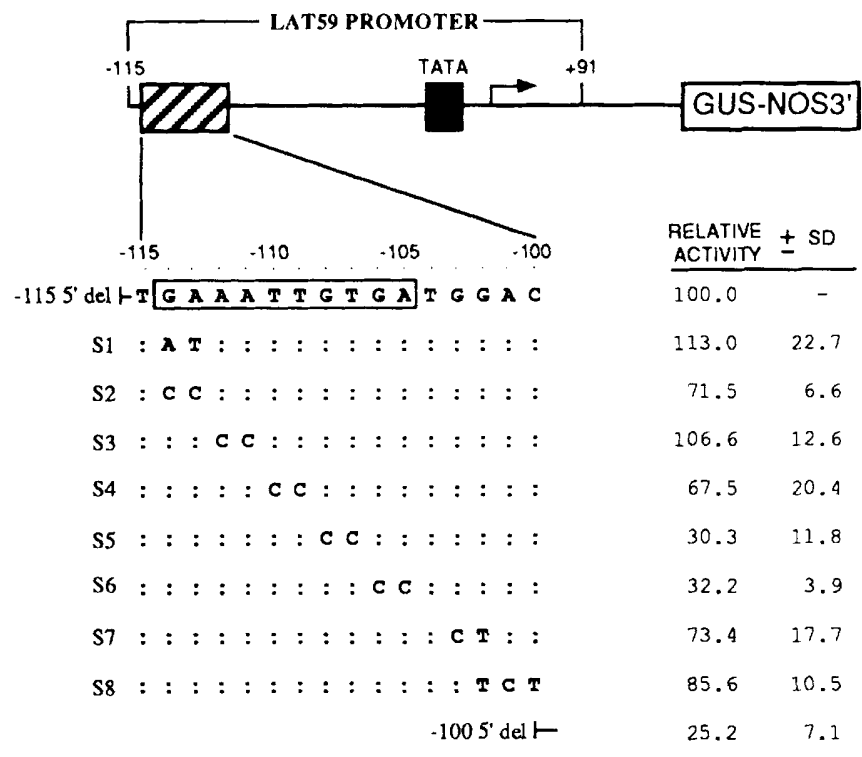


Tunen et al. 1989), the upstream promoter (chiA $\mathrm{P}_{\mathrm{A} 2}$ ) of which is sufficient to direct pollen-specific expression in petunia (van Tunen et al. 1990). In the $\mathrm{Zmgl} 3$ promoter, five sequences were found (at positions $-495 \mathrm{bp},-439$ bp, $-170 \mathrm{bp},-141 \mathrm{bp}$, and $-49 \mathrm{bp}$ ) that contained a GTGG motif and showed at least five of seven matches to the $\mathrm{PB}$ core motif. In the chi $\mathrm{P}_{\mathrm{A} 2}$ promoter, there are three sequences (at positions $-771 \mathrm{bp},-437 \mathrm{bp}$, and $-353 \mathrm{bp}$ ) that contained a GTGG motif and showed six of seven matches to the $\mathrm{PB}$ core motif. One sequence was found in the $\mathrm{Zmg} 13$ promoter (at $-81 \mathrm{bp}$ ) that showed 7 of 10 -bp matches to the $56 / 59$ box, while two such sequences (8- of 10-bp matches) were found (between - 111 and $-91 \mathrm{bp}$ ) in the chiA $\mathrm{P}_{\mathrm{A} 2}$ promoter.

\section{Discussion}

Pollen-and cell type-specific regulatory elements modulate LAT52 and LAT59 promoter activity

Our results (summarized in Fig. 4) demonstrate that only minimal promoter proximal regions of the LAT52 $\mid-71$ to $+110 \mathrm{bp})$ and LAT59 $(-115$ to $+91 \mathrm{bp})$ genes are required for their correct, regulated expression during pollen development. Several upstream regulatory elements (52-A, 52-B, 59-A) appear to modulate the activity of these minimal promoters in pollen. Although this is the first analysis of the organization of cis-acting sequences that regulate gene expression during gametophyte development in plants, the promoter proximal location of sequences that determines tissue-specific expression in the sporophyte has been described for other plant genes (for review, see Benfey and Chua 1989). For instance, the soybean $\beta$-conglycinin gene requires only $159 \mathrm{bp}$ of upstream sequences to direct tissue- and stagespecific expression in seeds (Chen et al. 1986), while sequences farther upstream enhance transcription in a seed-specific manner. No evidence was obtained for negative regulatory elements that modulate LAT52 promoter activity in pollen or silence expression of the LAT52 promoter in sporophytic tissues. In contrast, deletion analysis of the LAT59 promoter in transgenic plants provides evidence for both positive (59-A) and negative (59-B) upstream regulatory elements that modulate gene expression in pollen (Fig. 4c). Because these putative regulatory elements did not display similar properties in the transgenic (in tomato) versus transient (in tobacco) analyses, further studies are required to confirm their properties and precise locations within the LAT59 promoter.

Our data also demonstrate that the LAT52 and LAT59 promoters are differentially activated in specific cell types of the sporophyte. Both promoters were expressed in the endosperm, but LAT59 was also expressed in the testa and root. The cis-acting sequences that mediate the observed activity of the LAT52 promoter in the endosperm $(52-\mathrm{C})$ are clearly different from those that mediate high level expression in pollen (52-A and 52-B; Fig. 4a). However, within the 52-C region, either the same or different sequences could mediate the activity of the
LAT52 promoter in pollen and endosperm. Similar arguments can be made for the pollen and sporophytic activity of the "minimal" LAT59 promoter. Studies of other tissue-specific genes provide evidence for a modular arrangement of distinct regulatory elements that mediate expression in different tissues. For instance, the tissuespecific expression of the Drosophila melanogaster white gene is independently controlled by different regulatory elements that are active in either the testes, the Malpighian tubules, or the eye (Levis et al. 1985).

In summary, our data indicate that the LAT52 and LAT59 promoters share a functionally similar promoter core but are modulated by several upstream regulatory elements that show differences in their organization and ability to enhance or repress gene expression in pollen or in certain sporophytic cell types. The fact that cell specificity was not lost upon progressive deletion of either promoter suggests that cell-specific expression is not achieved through a release from transcriptional repression. In contrast, in vitro transcription studies indicate that such a mechanism is responsible for the testis-specific expression of the mouse protamine 2 gene (Bunick et al. 1990). While we cannot rule out the possibility that general silencer elements are located within the core LAT52 and LAT59 promoters, we favor a regulatory mechanism based on the promotion or repression of transcription by several cell-specific trans-acting factors, which exert additive or combinatorial effects to achieve cell-specific expression. A similar regulatory mechanism is proposed for the cell-specific and synergistic activities of enhancer subdomains within the CaMV35S promoter (Benfey and Chua 1990).

\section{Function of the PB motif in the LAT52 upstream activation domain and its relationship with the GT-1 box}

Analysis in transgenic plants indicates that the LAT52 promoter is composed of two distinct domains, a proximal domain $(52-\mathrm{C})$, which determines tissue-specific expression (pollen and endosperm), and an upstream domain $(52-A+52-B)$ which is required for high-level expression specifically in pollen (Fig. 4a). Transient expression studies demonstrate further that sequences within the upstream domain 52-A2 (containing the PBII box) are able to activate either the minimal LAT52 promoter or the heterologous CaMV35S promoter in pollen, independent of orientation and, to some extent, independent of distance. It will be interesting to determine whether enhancer region 52-A2 or the PBII box alone is able to direct pollen-specific expression in transgenic plants. The reiterated PB motif in the LAT52 promoter domain is responsible, at least in part, for the functional redundancy of the LAT52 upstream region. Functional redundancy of upstream regions that mediate light-regulated and tissue-specific activity of the pea rbcs-3A gene appears to depend on the reiteration of the GT-1 box sequence (Kuhlemeier et al. 1988; Gilmartin et al. 1990). The similarity between the GT-1 box and the PB motif, together with the importance of the GG doublet 


\section{Twell et al.}

in both sequences (this paper and Green et al. 1988) suggests that GT-1 may also bind to the PB motif.

Two shared regulatory elements modulate the activity of the LAT gene promoters in pollen

Our results provide evidence for the function of two regulatory elements, the $52 / 56$ box and the $56 / 59$ box, which are shared among two of the three LAT gene promoters. However, we also demonstrated that the 52/56 box is dispensable for the developmental regulation of the LAT52 gene in pollen (Fig. 5B). On this basis we propose a quantitative role for the $52 / 56$ box, in which basal LAT52 and LAT56 promoter activity in pollen is coordinately enhanced by transcription factor(s) that recognize this sequence. The conserved $56 / 59$ box may also serve to activate basal promoter activity, and/or it may have a more determinative role in turning on expression of the LAT56 and LAT59 genes in pollen.

The similarity between functionally important nucleotides within the $52 / 56$ box (GTGG) and the $56 / 59$ box (GTGA) raises the possibility that they are both recognized by the same transcription factor(s). If so, this would provide a mechanism for the coordinate regulation of the LAT genes and perhaps other genes that are expressed late during pollen development. Indeed, the conservation of both the PB core motif and the $56 / 59$ box in the petunia chiA $\mathrm{P}_{\mathrm{A} 2}$ promoter would indicate a more "global" role for these sequences in coordinating gene expression late during pollen development. Isolation and characterization of trans-acting factors that regulate LAT gene expression will allow direct testing of regulatory mechanisms and their relationship to other factors, such as GT-1. Such studies should provide further insight into the molecular events that are required for the establishment of differential and coordinate patterns of gene expression during male gametophyte development.

\section{Materials and methods}

\section{Plant transformation}

Agrobacterium strains containing gene fusion constructs were used to infect cotyledons of Lycopersicon esculentum cv. VF36, and kanamycin-resistant plants regenerated as described (Twell et al. 1990), but using $375 \mu \mathrm{M}$ acetosyringone. Eight to 15 independently transformed plants were obtained for each gene fusion, except for the -3000 -bp LAT52-GUS construct, for which only four transformants were obtained.

\section{Construction of plasmids}

To construct 5' deletion mutants of the LAT promoters, restriction sites were introduced by polymerase chain reaction (PCR), using oligonucleotide primers with restriction sites at their $5^{\prime}$ ends and LAT promoter sequences with the desired mutation at their $3^{\prime}$ ends. Along with each mutant primer, a second primer corresponding to the nonsense strand of the GUS gene at position -70 bp plus the appropriate template $(-492$ bp 52 -GUS, -318 bp $56-$ GUS, or -1305 bp 59-GUS) was used to synthesize a PCR product that was cleaved, purified, and cloned into a promoterless GUS-NOS plasmid (pDAT-1 or pGP213; Twell et al. 1989a, 1990). The LAT52 and LAT56 deletion mutants contained the entire 5 '-most untranslated leader sequences fused to the translational start codon of the GUS gene. All of the LAT59 mutants contained only the $5^{\prime} 91 \mathrm{bp}$ of the 234-bp 5 '-untranslated leader.

Selected 52-GUS-NOS3' and 59-GUS-NOS3' deletion mutants were cloned into binary vector pBIN19 (Bevan 1984) and transferred to the disarmed Agrobacterium tumefaciens strain PC2760 (pAL4404) as described (Twell et al. 1990). Internal deletion mutants of the LAT promoters were constructed by using a strategy similar to the PCR scheme described above. Hybrid LAT52-CaMV35S promoter fusions were constructed by cloning PCR fragments of the LAT52 gene or a double-stranded oligonucleotide into the XhoI site of plasmid pJO4X $(-89$ bp CaMV35S-LUC; Ow et al. 1986).

All PCR products were entirely sequenced. No errors were found in constructs containing LAT52 and LAT59 promoter sequences. However, two different base changes were detected in the untranslated leader sequence of the LAT56 constructs. These mutant constructs showed no significant differences in their activities in transient assays when compared with versions in which these changes were subsequently corrected to the wild-type LAT56 leader sequence.

The - 300-bp CaMV35S-GUS fusion used as a control for seed expression was constructed (by Margaret Boylan) by cloning the GUS-coding region from pBI101.I (Jefferson et al. 1987) into the polylinker of plasmid pMON316 (Rogers et al. 1987) between the CaMV35S promoter and nos gene polyadenylation/ termination sequences.

\section{Transient expression assays in pollen}

Plasmids were introduced into mature tobacco pollen by microprojectile bombardment as described (Twell et al. 1989a), except that $\sim 10^{7}$ pollen grains $(0.5 \mathrm{ml}$ of a 20 -to $40-\mathrm{mg}$ dry weight $/ \mathrm{ml}$ MSO medium pollen suspension/ were used per bombardment. Tobacco was used in these experiments because the LAT52 and LAT59 promoters were shown to function similarly in tomato and tobacco, both in transgenic plants and in transient assays (Twell et al. 1989a, 1990; McCormick et al. 1991) and because large quantities of tobacco pollen can be collected easily.

Test promoter constructs linked to the GUS gene were coprecipitated onto tungsten microprojectiles with a reference plasmid (pLAT59-13; Twell et al. 1990) containing the - 1305-bp to +91-bp LAT59 promoter fused to the firefly luciferase (LUC) gene (Ow et al. 1986). Test promoter activity was expressed as a ratio of GUS to LUC activity and normalized to the activity of one of the LAT-GUS deletion mutant plasmids. Bombardment of pollen with microprojectiles coated with increasing amounts of test plasmid DNA led to a linear increase in activity in the range of 2-15 $\mu \mathrm{g}$ for the 52-, 56-, and 59-GUS fusions (McCormick et al. 1991). The amount of DNA introduced $(7 \mu \mathrm{g}$ of test plasmid and $2 \mu \mathrm{g}$ of reference plasmid) was chosen to be within the linear range. LAT52 and LAT59 bombardments were assayed after 6-7 hr. Longer incubations $(12 \mathrm{hr})$ and higher amounts of DNA $(14 \mu \mathrm{g})$ were used for LAT56 constructs to increase the sensitivity of the assay, since the LAT56 promoter was appropximately fourfold less active than the LAT59 promoter (McCormick et al. 1991). Pollen was extracted in $0.5 \mathrm{ml}$ of buffer [0.1 $\mathrm{M} \mathrm{KPO}_{4}$ (pH 7.5), $1 \mathrm{~mm}$ dithiothreitol], and assayed for GUS and LUC activity as described (Twell et al. 1990).

\section{Histochemical localization of GUS activity}

Localization of GUS activity in sections of anthers, seeds, and root segments was carried out as described (Twell et al. 1990). 
Seeds and anthers were incubated in $1 \mathrm{~mm} \mathrm{X}$-Gluc for $4 \mathrm{hr}$ at room temperature; roots were incubated under the same conditions overnight.

\section{Acknowledgments}

We thank Theodore M. Klein for assistance with pollen bombardments, Margaret Boylan for the use of CaMV35S-GUS transformed tomato plants, David $O w$ for the use of CaMV35S-LUC-NOS3' plasmids, Peter Quail, Katayoon Dehesh, Keith Hamby, and Guy Vancanneyt for critical reading of the manuscript, and E.I. DuPont \& Co., Medical Products Division, for the use of the Biolistic PDS-1000 particle delivery system. This work was supported by U.S. Department of Agriculture/Agricultural Research Service CRIS number 533522230-002-00D, and by the National Science Foundation Center for Plant Developmental Biology, University of California, Berkeley, DIR-8719933. Sequence data described in this paper were submitted to the EMBL/Genbank Data Libraries under accession numbers X56487 (LAT56) and X56488 (LAT59).

The publication costs of this article were defrayed in part by payment of page charges. This article must therefore be hereby marked "advertisement" in accordance with 18 USC section 1734 solely to indicate this fact.

\section{References}

Benfey, P.N. and N.-H. Chua. 1989. Regulated genes in transgenic plants. Science 244: 174-181.

. 1990. The Cauliflower mosaic virus 355 promoter: Combinatorial regulation of transcription in plants. Science 250: 959-966.

Bevan, M. 1984. Binary Agrobacterium vectors for plant transformation Nucleic Acids Res. 12: 8711-8721.

Bunick, D., P.A. Johnson, T.R. Johnson, and N.B. Hecht. 1990. Transcription of the testes-specific mouse protamine 2 gene in a homologous in vitro transcription system. Proc. Natl. Acad. Sci. 87: 891-895.

Chen, Z.-L., M.A. Schuler, and R.N. Beachy. 1986. Functional analysis of regulatory elements in a plant embryo-specific gene. Proc. Natl. Acad. Sci. 83: 8560-8564.

Gilmartin, P., L. Sarokin, J. Memelink, and N.-H. Chua. 1990. Molecular light switches for plant genes. Plant Cell 2: 369378.

Green, P.J., M.-H. Yong, M. Cuozzo, Y. Kano-Murakami, P. Silverstein, and N.-H. Chua. 1988. Binding site requirements for pea nuclear protein factor GT-1 correlate with sequences required for light-dependent transcriptional activation of the rbcS-3A gene. EMBO /. 7: 4035-4044.

Hamilton, D.A., D.M. Bashe, J.R. Stinson, and J.P. Mascarenhas. 1989. Characterization of a pollen-specific genomic clone from maize. Sex. Pl. Reprod. 2: 208-212.

Hanson, D.D., D.A. Hamilton, J.L. Travis, D.M. Bashe, and J.P. Mascarenhas. 1989. Characterization of a pollen-specific cDNA clone from Zea mays and its expression. Plant Cell 1: 173-179.

Jefferson, R.A., T.A. Kavanagh, and M.W. Bevan. 1987. GUS fusions: $\beta$-Glucuronidase as a sensitive and versatile gene fusion marker in higher plants. $E M B O /$. 6: 3901-3907.

Kuhlemeier, C., M. Cuozzo, P.J. Green, E. Goyvaerts, K. Ward, and N.-H. Chua. 1988. Localization and conditional redundancy of regulatory elements in rbcS-3A, a pea gene encoding the small subunit of ribulose-bisphosphate carboxylase. Proc. Natl. Acad. Sci. 85: 4662-4666.

Levis, R., T. Hazelrigg, and G. Rubin. 1985. Separable cis-acting control elements for expression of the white gene of Drosophila. EMBO I. 4: 3489-3499.

Mascarenhas, J.P. 1975. The biochemistry of angiosperm pollen development. Bot. Rev. 41: 259-314.

- 1988. Anther- and pollen-expressed genes. In Temporal and spatial regulation of plant genes (ed. D.P.S. Verma and R.B. Goldberg), pp. 97-115. Springer-Verlag, New York.

1989. The male gametophyte of flowering plants. Plant Cell 1: 657-664.

McCormick, S., A. Smith, C. Gasser, K. Sachs, M. Hinchee, R. Horsch, and R. Fraley. 1987. The identification of genes specifically expressed in reproductive organs of tomato. In Tomato biotechnology (ed. D. Nevins and R. Jones), pp. 255265. A.R. Liss, New York.

McCormick, S., J. Yamaguchi, and D. Twell. 1991. Deletion analysis of pollen-expressed promoters. In vitro cellular and developmental biology plant. 27 (in press).

Ow, D.W., K.V. Wood, M. DeLuca, J.R. DeWet, D.R. Helinski, and S.H. Howell. 1986. Transient and stable expression of the firefly luciferase gene in plant cells and transgenic plants. Science 234: 856-859.

Rogers, S.G., H.J. Klee, R.D. Horsch, and R.T. Fraley. 1987. Improved vectors for plant transformation. Methods Enzymol. 153: 253-277.

Sassone-Corsi, P. and E. Borrelli. 1986. Transcriptional regulation by trans-acting factors. Trends Genet. 2: 215-219.

Twell, D., T.M. Klein, M.E. Fromm, and S. McCormick. 1989a. Transient expression of chimeric genes delivered into pollen by microprojectile bombardment. Plant Physiol. 91: 12701274.

Twell, D., R.A. Wing, J. Yamaguchi, and S. McCormick. 1989b. Isolation and expression of an anther-specific gene from tomato. Mol. Gen. Genet. 217: 240-245.

Twell, D., J. Yamaguchi, and S. McCormick. 1990. Pollen-specific gene expression in transgenic plants: Coordinate regulation of two different tomato gene promoters during microsporogenesis. Development 109: 705-713.

van Tunen, A.J., S.A. Hartman, L.A. Mur, and N.M. Mol. 1989. Regulation of chalcone flavone isomerase $(\mathrm{CHI})$ gene expression in Petunia hybrida: The use of alternative promoters in corolla, anthers and pollen. Plant Mol. Biol. 12: 539-551.

van Tunen, A.J., L.A. Mur, G.S. Brouns, J.-D. Rienstra, R.E. Koes, and J.N.M. Mol. 1990. Pollen- and anther-specific promoters from petunia: Tandem promoter regulation of the chiA gene. Plant Cell 2: 393-401.

Wing, R.A., J. Yamaguchi, S.K. Larabell, V.M. Ursin, and S: McCormick. 1989. Molecular and genetic characterization of two pollen expressed genes that have sequence similarity to pectate lyases of the plant pathogen Erwinia. Plant Mol. Biol. 14: 17-28. 


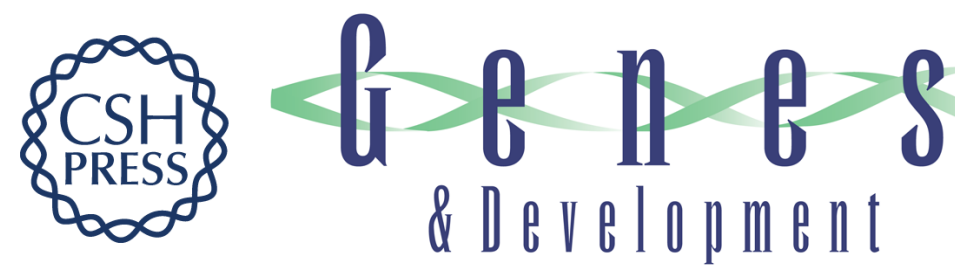

\section{Promoter analysis of genes that are coordinately expressed during pollen development reveals pollen-specific enhancer sequences and shared regulatory elements.}

D Twell, J Yamaguchi, R A Wing, et al.

Genes Dev. 1991, 5:

Access the most recent version at doi:10.1101/gad.5.3.496

References This article cites 23 articles, 12 of which can be accessed free at:

http://genesdev.cshlp.org/content/5/3/496.full.html\#ref-list-1

License

Email Alerting Receive free email alerts when new articles cite this article - sign up in the box at the top Service right corner of the article or click here.

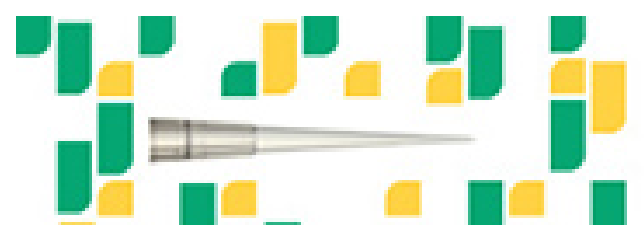

Focused on your science. 